\title{
La peste como catástrofe y palingenesia en la literatura italiana (y no sólo)
}

\author{
Mariapia LAMBERTI \\ Universidad Nacional Autónoma de México
}

\begin{abstract}
La peste ha sido descrita por diferentes escritores en el transcurso de los siglos, entendida como catástrofes de plúrimas consecuencias: no última la regeneración de la sociedad. Tucídides en época clásica, Boccaccio en la Edad Media, Manzoni en época romántica y finalmente Camus en época contemporánea dedican sus obras maestras a la descripción de la plaga y a sus consecuencias.

Palabras Clave: Peste, Tucídides, Boccaccio, Manzoni, Camus.

The plague has been described many times during centuries: sometimes it has been only visualized as a catastrophy, but also like a cause of regeneration of humanity. Tucydides on classical Greece, but also Boccaccio in Middle Age, Manzoni at the Romantical era, and eventually Camus in modern times have dedicated their literary art at plague description - and interpretation of its consecuences.
\end{abstract}

KEY WORDS: Plague, Tucydides, Boccaccio, Manzoni, Camus.

No es el pueblo italiano muy inclinado a la mística, ni a dejarse ir a temores colectivos de apocalipsis. Hasta sus escritores más religiosos, como san Francisco de Asís, considerado tradicionalmente el primer poeta de nuestra historia literaria oficial, en sus alabanzas a Dios se refiere más bien a todas sus criaturas. Y las profecías o los temores del fin del mundo, aunque hayan circulado en Italia como en todas partes, no tuvieron ni tanto impacto ni tantos seguidores como en otras poblaciones de Europa. El mismo Gioacchino da Fiore, quizá el teólogo más interesado en las cuestiones milenarísticas y apocalípticas, prolonga la visión de la duración temporal del mundo más que otros visionarios de sus tiempos.

Pero además de las previsiones de un final del mundo por directa intervención divina, un real fenómeno destructor ha conocido la humanidad desde los tiempos más remotos, que en concreto provoca una muerte multitudinaria: la peste. Y es interesante ver cómo en la literatura italiana se ha dedicado atención a este fenómeno en dos ocasiones célebres; aunque en otros tiempos y literaturas encontramos descripciones de la peste.

Es éste un nombre genérico, pues se han denominado en esta forma epidemias de enfermedades que hoy la ciencia médica cataloga en formas diferentes. Estos flagelos 
se han rememorado en textos históricos antiguos como la Biblia: Dios manda la peste sobre los Filisteos que se han apoderado del Arca de la Alianza (Samuel, 1), y hace morir de peste a setenta mil hebreos (Samuel, 24), porque David ha escogido, entre tres castigos que Yahveh le propone, el de tres días de peste. Se conoce este flagelo en la historia de Egipto, y finalmente se tiene su primera descripción célebre, en nuestra cultura, por parte del historiador griego Tucídides (460-396 a. C.). Éste nos deja una descripción de la plaga que azotó a los atenienses en el transcurso de su larga guerra (431-404) contra los espartanos: esta Guerra del Peloponeso está relatada con precisión de crónica y con elegancia literaria por Tucídides, que crea, se puede decir, el estilo historiográfico de la antigüedad: a la descripción puntual de los hechos, se acoplan los juicios sobre las causas y las consecuencias (perspectivas que hoy caracterizan el periodismo político) y las recreaciones de los discursos de los protagonistas destacados de los hechos; algo que hoy consideraríamos literatura de creación, no crónica histórica: pero comprensible como técnica en una época donde el registro puntual de los discursos era imposible.

La descripción de la peste en Atenas de Tucídides es, se podría decir, como el modelo, o el antecedente imprescindible a examinar, porque en él se delinean los puntos fundamentales de las descripciones posteriores de este fenómeno, de las que en la literatura occidental se rememoran principalmente tres, por su calidad y excelencia: la de Giovanni Boccaccio en el Decameron, la de Alessandro Manzoni en I promessi sposi y la de Albert Camus en La peste. Como se ve, de tres descripciones célebres después de la de Tucídides, dos son italianas.

\section{Tucídides}

En los años que denominamos 430-429 antes de nuestra era, durante la larga guerra que se libró entre Atenas y Esparta, en tres etapas, nos narra Heródoto que, en el momento en que los peloponesios invadieron Ática, empezó entre los Atenienses una mortandad tremenda, por primera vez. Tucídides, con buena paz de los traductores, que usan los términos peste, pestilencia, y cuantos sinónimos hay, usa sencillamente la

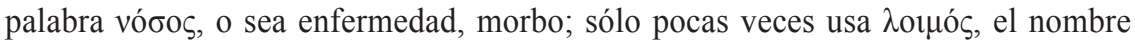
propio del padecimiento. Y cuando tiene que referirse a ello después, trata de no nombrarlo, dice: aquello, lo mismo. Dice haberlo padecido y haber sanado: y empieza a describir minuciosamente la sintomatología, para que - se justifica - en el futuro se pueda reconocer este mal y ponerse en guardia.

Encontramos en esta descripción — que en el segundo libro, relativo al segundo año de guerra, ocupa los parágrafos del 47 al 54- elementos importantes, que reconoceremos en las sucesivas descripciones de epidemias mortales.

Se menciona el origen lejano del contagio: en este caso, Etiopía y Egipto; su difusión inicial en zonas suburbanas (Tucídides menciona El Pireo, carente de agua potable) donde la gente vive en condiciones higiénicas precarias; y su llegada en la gran 
ciudad sin ya distinción de clase social y comodidades de vida, aunque haciendo mayor estrago entre los hacinamientos de los prófugos del campo, que venían a refugiarse en la ciudad, sin casas donde vivir. Entre los síntomas descritos, y afirmando que la mortandad mayor se debía al contagio (los más numerosos en morir, nos dice, eran los médicos que trataban a los enfermos), nos relata algo que impresiona: hasta los animales que normalmente se alimentan de cadáveres (aves o canes) se abstenían de comer a los muertos de peste abandonados, y si lo hacían, morían.

Tucídides es hombre de razón y cultura: hoy lo definiríamos un laico. Su descripción médica es precisa - aunque él remita a los galenos toda conclusión con respecto a la enfermedad - pero sobre todo importa su visión del fenómeno como algo natural, sin relación con la divinidad: de allí su investigación minuciosa. Sin embargo, nos da noticia de los rituales religiosos para invocar la ayuda de los dioses, al inicio de la plaga; pero — nos dice — al ver que de nada servían se renunció a estas prácticas. Y no las vuelve a mencionar.

Pero lo más importante es la descripción de los comportamientos de la gente, sanos y enfermos. Los enfermos, desesperados, pierden fuerzas frente a la enfermedad por su misma desesperación. Y los vivos y aún sanos tienen varias actitudes: se portan nobles con sus amigos enfermos, y se enferman y mueren con ellos; o los evitan y se encierran en soledad, abandonan a su suerte a los enfermos (pero, nos advierte el historiador, los enfermos morían con o sin asistencia), y aun así no escapan al contagio; o bien pierden todo respeto por la muerte, y abandonan los cadáveres, los avientan sobre las piras funerarias ajenas, los dejan amontonados en los lugares sagrados sin ningún respeto.

Pero hay algo tremendo en la descripción de Tucídides y característico de todas las situaciones de análoga tragicidad, que se verificarán después: ${ }^{1}$

La enfermedad dio la señal de inicio del difundirse de la inmoralidad. Los instintos, antes ocultados, se desataron sin freno ante el espectáculo de los súbitos cambios: de unos ricos muertos repentinamente, y unos pobres en extremo [que se volvieron] herederos de golpe. Vida y dinero tenían a los ojos de la gente el mismo efímero valor. Lo que se quería era gozar: rápida, materialmente. Gastar tiempo y esfuerzo para un propósito digno, cuando su alcance podía verse impedido por la muerte, no atraía a nadie. El goce inmediato y todo lo que facilitara su alcance: esto solo parecía útil y digno. El temor de los dioses, o la ley de los hombres no detenían a nadie. Impiedad o religión eran lo mismo para quien veía que todos perecían por igual. Y por lo que respecta al castigo de las culpas, nadie esperaba vivir tanto como para pagarlas: una sentencia mucho más tremenda se cernía sobre sus cabezas; y antes que la hora sonara valía la pena haber vivido (Tucídides: 207. II-53).

\footnotetext{
${ }^{1}$ He consultado el texto griego y una traducción italiana. Ésta no tiene el esquematismo pujante del texto griego, pero es clara y emotiva. Prefiero dar aquí mi versión en español de esta traducción italiana (de la que modifiqué algunas estructuras siguiendo el texto griego), ya que también las citas de Boccaccio se darán en español, aunque de una traducción autorizada.
} 
Veremos descrita esta actitud en los grandes escritores de la peste que vendrán, así como la búsqueda insensata de culpables: algo que Tucídides no menciona, demostrando así su superioridad intelectual y la de sus compatriotas.

\section{Boccaccio}

Tenemos que llegar al siglo XIV para encontrar la pestilencia más tremenda que se recuerde en la historia de la humanidad. Empezó en oriente lejano, en China, por un conjunto de situaciones climáticas que favorecieron la vitalidad de la bacteria causante. Llegó a orillas del Mediterráneo en 1347 con la Horda de Oro de Ganī Bek que puso sitio a Jaffa sobre el Mar Negro. Se relata que los mongoles aventaron cadáveres de muertos de peste de su ejército dentro los muros de la ciudad. Las galeras de los genoveses que dejaron luego la ciudad llevaron el morbo a los otros puertos del Mediterráneo, y la consecuencia fue que en 1348 la peste se había difundido en toda Europa, y entre un tercio y la mitad de la población europea se extinguió, con una mortandad de casi $100 \%$ de los afectados. Si Tucídides evita mencionar que el mismo Pericles fue víctima de la enfermedad en 429, nosotros podemos en cambio recordar que entre los millones de muertos se encontraba Laura, la amada de Petrarca. En todas las regiones del norte de Europa se difundió el sentimiento del fin del mundo, se vio multiplicarse la imaginería de la Muerte, la Muerte Negra, las danzas macabras (la danse des maccabées, o sea de los difuntos); procesiones, consorterías de flagelantes, rezos desmodados, trataron de aplacar la ira divina a la que se atribuía el flagelo; pero también la feroz búsqueda de presuntos culpables terrenales llevó a persecuciones crueles y homicidas, contra las supuestas brujas y contra los judíos, que sufrieron su primer pogrom generalizado: muchos de ellos, en diferentes ciudades del norte de Europa, prefirieron suicidarse incendiando sus casas, a caer en manos de sus despiadados persecutores.

Y no es posible no mencionar a este propósito la estupenda película de Ingmar Bergman El séptimo sello, un clásico del cine donde se concentran todos estos elementos visuales y espirituales en una inquietante metáfora de la vida humana de todos los tiempos.

Pero el fenómeno en Italia, en la solar Italia, dio un resultado muy poco acorde con la dramática y apocalíptica sensibilidad del norte.

Giovanni Boccaccio (1313-1375) es considerado el más importante escritor en prosa de la Edad Media, y no sólo por lo que respecta a Italia y su literatura. Espíritu despreocupado, en la primera mitad de su vida, de los asuntos religiosos, escribe en verso y en florentino sus primeras obras, unos poemas narrativos; pero encuentra su verdadera forma y grandeza literaria en la prosa, con los cien cuentos que configuran el Decameron, que ve la luz en 1350, el último año de la peste negra. Sus cuentos o novelle, como entonces se decía - entendiendo con el término noticias, hechos verídicos desconocidos o conocidos, pero novedosos, singulares - han sido fuente de inspiración para muchos escritores posteriores. Baste recordar que la lengua literaria 
de Boccaccio ha sido durante siglos la base de la lengua literaria en prosa de Italia, territorio dividido no sólo política, sino también lingüísticamente hasta tiempos recientes. Pero menos se recuerda la genial estructura narrativa en la que se insertan y justifican las cien novelle. El libro, después de una halagadora dedicatoria a las mujeres, a las que los cuentos están destinados como solaz y consuelo por el autor, recién liberado de las penas de amor, empieza a narrarnos la primera de las diez jornadas en las que diez jóvenes - siete mujeres y tres hombres, una prevalencia significativa del bello sexo- se cuentan historias placenteras, por el total de cien. Es lo que se llama "marco", un artificio que da unidad y lógica a la sucesión de los cuentos, un artificio que otros autores posteriores emplearán, desde Chaucer hasta Calvino.

Pero esta primera jornada tiene un preámbulo. En la cuidada traducción de Esther Benítez:

Cuando me abandono a mis pensamientos y considero, graciosísimas señoras, vuestra natural sensibilidad, me doy cuenta que esta obra tendrá, en vuestra opinión, un comienzo pesado y enojoso, pues os recordará el hecho doloroso de la mortífera peste pasada, tan dañosa y lastimera para quienes la sufrieron o supieron de ella de otro modo. Mas no querría que eso os hiciera desistir de la lectura [...]. Este horrible comienzo será sólo como una montaña escarpada y pina, pasada la cual el caminante halla una llanura bellísima y riente, que le resultará tanto más grata cuanto más haya penado en la subida y la bajada (Boccaccio: 15).

Y concluye esta disculpa inicial así: "era necesario este preámbulo para comprender todo lo que después se leerá, y empujado por la necesidad, me dispongo a escribirlo" (16).

Considera entonces nuestro autor una necesidad describir la trágica plaga antes de sumirse en la atmósfera amable, amorosa y por momentos divertida e irreverente de sus cuentos que retratan la vida y el mundo en su aspecto más placentero.

Empieza entonces la segunda descripción de la peste que ha dejado huella en la literatura occidental. Las páginas que nos deja Boccaccio son singularmente análogas a la descripción de Tucídides, aunque no hay que pensar en una lectura por parte del italiano, pues en su época muchos textos griegos no se podían leer por desconocimiento de la lengua (Boccaccio intentó aprenderla por su cuenta, y tenemos un cuaderno suyo que lo demuestra, así como los nombres seudogriegos de su obra y de sus personajes), y no sabemos si traducciones latinas se encontraban al alcance.

Sigámoslo. Boccaccio inicialmente menciona, casi como un homenaje debido a las creencias de sus tiempos, las explicaciones místicas de la plaga, pero lo hace con una frase adjetiva subordinada a la oración principal, en la que se da su origen - su punto de origen - terrenal: "Producida por influencia de los astros o enviada a los mortales por la justa ira de Dios para corrección de nuestras iniquidades, se había iniciado años antes en Oriente" (16).

Sigue constatando cómo ningún remedio valiera contra ella, ningún "saber ni providencia humana" (16), ni la limpieza de las ciudades, ni la prohibición de la entrada 
en ellas de los enfermos, ni los consejos médicos (nota, en otro pasaje más adelante, que nadie de hecho sabía ni qué causaba la enfermedad, ni en qué consistía: "la ignorancia de quienes lo medicaban [...] nada sabía de sus causas" [17]); y menciona, muy de pasada, que tampoco servían los rituales piadosos de conjuro: "ni siquiera las humildes súplicas dirigidas a Dios por las personas devotas, no una vez sino muchas, en procesiones ni en otra guisa" (16). No nombra a los flagelantes, ni las injustas acusaciones sobre supuestos difusores de la peste, permitiéndonos deducir con alivio que tales excesos no se dieron en Florencia. Pasa de inmediato a describir los síntomas: diferentes en parte de los descritos por Tucídides, más acordes con lo que llamamos peste bubónica. Entre estos síntomas menciona, como ya había hecho el ilustre griego, la facilidad de transmisión: "Esta pestilencia tuvo tanta más fuerza porque se propagaba de las personas enfermas a las sanas con la misma prontitud con que se propaga el fuego a las cosas secas o engrasadas [...]. Y aún hubo más, pues no sólo el hablar o el tener trato con los enfermos contagiaba a los sanos, sino también el tocar las ropas o cualquier otra cosa tocada o utilizada por los apestados parecía transportar tal enfermedad hasta el que la tocaba" (17).

A continuación nos relata algo que ya había dicho Tucídides: "Digo que la pestilencia mencionada tuvo tan grande fuerza de contagio, que no sólo se pegaba de un hombre a otro, sino que (y esto ocurrió visiblemente en más de una ocasión), cuando algún animal de otra especie que hombre tocaba algo perteneciente a un apestado o a un muerto de la enfermedad, se contaminaba en muy breve tiempo, y moría enseguida" (17). Y narra cómo él mismo vio morir así a dos cerdos.

Después de esta descripción fisiológica es el turno de las consecuencias morales de tanto horror. Ya conocemos estos detalles siniestros: el abandono de los enfermos, el recluirse en lugares aislados (dice Boccaccio que muchas casas eran abandonadas, y que cualquiera entraba en la casa de otro para aprovecharse de lo que allí encontraba), creyendo con eso asegurar su salud. En sus palabras: "Había quienes pensaban que la sobriedad y la moderación les harían resistir la desgracia"; tales personas, nos dice el autor, se reunían en grupos en casas sin enfermos, "usaban con gran templanza de comidas delicadísimas y óptimos vinos, huían de los excesos y, sin permitir que nadie hablase o trajese noticias de fuera, de muerte o enfermos, se entretenían con la música y los placeres que podían tener" (18). Es el comportamiento que, podemos intuir desde aquí, tendrán los diez jóvenes que protagonizarán la historia-marco de las cien novelle. Pero Boccaccio no se detiene aquí: prosigue dándonos, en la oración siguiente, el comportamiento opuesto: "Otros, inclinados a la opinión contraria, afirmaban que la mejor medicina para tanto mal era beber mucho, disfrutar, cantar y divertirse, satisfacer lo mejor posible todos los caprichos y reírse o burlarse de cuanto ocurría" (18). Y he aquí las borracheras, la invasión ya mencionada de las casas vacías; y sigue el escritor con tonos siempre más trágicos, mencionando la falta absoluta de respeto a las leyes humanas o divinas sin control; el egoísmo absoluto, el descuido de familiares o amigos (hasta de esposas y maridos, padres e hijos, nos dice), la muerte sin asistencia, a menudo en la calle, y sin las honras fúnebres acostumbradas. No sólo: sino que nos 
habla Boccaccio por primera vez de fosas comunes, enormes, llenas de cadáveres y cubiertas sólo con un velo de tierra, a cargo de unos "enterradores [beccamorti], salidos del bajo pueblo, que se hacían llamar 'sepultureros' [becchini $\left.i^{2}\right]$ " (21). Menciona el 'bajo pueblo': dice Boccaccio que fue, obviamente, el más castigado: "Mucho más miserable era el espectáculo de la gente baja y aún de la mediana; éstos, retenidos en sus casas por la esperanza o la pobreza, se quedaban en sus barrios y enfermaban por millares cada día; faltos de cuidados y de toda ayuda, morían casi sin remisión" (21). Y la plaga, dice el autor, "no ahorró sufrimiento a la comarca circundante". Nos describe cómo la peste ataca al campo, y los campesinos abandonan sus labores y sus animales domésticos, que viven ya como bestias salvajes: "Los bueyes, los asnos, las ovejas, las cabras, los cerdos, los pollos y los propios perros, fidelísimos al hombre, expulsados de las casas, vagabundeaban por los campos" (22-23).

Sigue una última visión de la ciudad, donde "fue tan grande la crueldad del cielo y acaso en parte la de los hombres, que entre los meses de marzo y julio se da por seguro que perdieron la vida dentro de las murallas de la ciudad de Florencia más de cien mil criaturas humanas, unas por la fuerza de la pestífera enfermedad y otras por verse mal cuidadas y abandonadas a causa del miedo que tenían los sanos" (23); y después de haber rememorado "cuántos memorables linajes, cuántas opulentas herencias, cuántas célebres riquezas" se quedaron sin sucesor, o destruidos, nos dice una frase inquietante que se corresponde a la primera que hemos citado: "Yo mismo lamento tener que entretenerme con tantas desdichas" (23).

¿Por qué siente Boccaccio que tiene que entretenerse narrando esta tragedia que ya no será rememorada ni con una sola mención en los días sucesivos? Días en que los diez jóvenes se entretendrán con señorial elegancia contándonos historias, sin rebajarse a un solo exceso, sin trenzar entre ellos una relación que rebase mínimamente los límites de una cordial y respetuosa amistad. Entonces, si en el texto ya no se hace mención del flagelo, ¿por qué Boccaccio considera necesaria su minuciosa descripción previa?

Sé por experiencia que sus imágenes y el halo de la Muerte se quedan presentes en la mente del lector, y cada gota de ese elixir de vida que es la sucesión de las narraciones del Decameron cobra realce en el contraste.

La palingenesia después de la destrucción es más clara que la que los historiadores modernos quieren reconocer en los cambios profundos que en lo social, lo económico y lo tecnológico intervinieron después de la gran peste negra en Europa. Sus deducciones y lazos causa-efecto se pueden discutir, negar o profundizar. ${ }^{3}$ Pero nadie puede

\footnotetext{
${ }^{2}$ En realidad las dos palabras son populares y no tienen el nivel, las 'seriedad' etimológica que en español tienen enterrador y sepulturero. Beccamorto literalmente significa "pica, pellizca muertos" y becchino es su derivado reducido: "picador, pellizcador".

${ }^{3}$ Se dijo hasta que las búsquedas tecnológicas que culminaron con la invención de la imprenta tuvieron un impulso muy importante por la falta de amanuenses después de la mortandad. Sin embargo, la imprenta se inventó casi un siglo después de la peste. Lo seguro es que la disminución de la mano de obra y el deseo de mantener de todos modos sometidos económica y políticamente a los trabajadores asalariados provocó el primer movimiento obrero de la historia europea, Il tumulto dei Ciompi, Florencia, 1378.
} 
poner en duda el valor vital de la obra de Boccaccio: en ella se encuentra todo lo más esplendoroso, juvenil y entusiasmante de la vida humana: y hasta las desdichas y la muerte (que no faltan) se tiñen de la luz del Amor, de la Fortuna, de la habilidad triunfante de la mente humana. Y sin este contraste implícito, siempre presente, no tendrían ni la fuerza ni el impacto que tienen.

\section{Manzoni}

La otra gran descripción de la peste que encontramos en la literatura italiana tiene una peculiaridad fundamental que la distingue de las dos anteriores examinadas. Quien escribe no es contemporáneo del flagelo, lo ha estudiado en los textos históricos y cronaquísticos de una época para él pasada.

Alessandro Manzoni (1785-1873) comparte con Giovanni Boccaccio el nombre de padre de la lengua italiana: si Boccaccio nos dejó un modelo insuperable de lengua que funcionó como tal durante siglos, Manzoni ha fijado, con elegancia y precisión inigualables, la lengua moderna, finalmente viva, la que todos hablamos y que enfrenta las mutaciones naturales que el tiempo y los acontecimientos conllevan.

Educado en el ambiente ilustrado más adelantado de Italia, el de Milán, abandonó su ideología dieciochesca, indiferente al problema religioso, para adherirse con seriedad y profundidad al catolicismo. Un catolicismo teológicamente castizo, alejado de toda complacencia sentimental y vertientes supersticiosas: con una veta rigorística que le derivaba de haber adherido inicialmente, en su búsqueda de Dios, al calvinismo. Contemporáneamente a esta conversión religiosa se manifestó la conversión literaria: adhirió al movimiento romántico, y a los modos y estructuras de la novela histórica, muy en boga en el principio del siglo XIX. Pero a la novela histórica como se manifestaba en aquellos decenios, agregó unos matices que otorgaron una significativa plusvalía al género: por un lado la precisión y exhaustividad de las investigaciones históricas, y por otro un valor moral elevado: el episodio del pasado que la novela iba a tratar, debía de significar para los lectores del presente una enseñanza clara, presentar un paralelismo con la situación actual que fuera motivo de reflexión. Escoge por lo tanto para su obra maestra universal, I promessi sposi, el periodo de la dominación española, en Milán y la Lombardía, del siglo XVII, análoga a la dominación austriaca que se padecía en sus tiempos en la misma zona de Italia, para fomentar el espíritu independentista en sus contemporáneos; y del siglo XVII escoge, para ubicar su historia de prevaricación de los poderosos sobre los humildes, los años inmediatamente anteriores y los de la máxima virulencia de la peste bubónica que, como la del siglo XIV, asoló y diezmó a Europa: 1628-1631.

Por lo tanto, Manzoni describe en su novela todos los antecedentes que presagian el mal: la carestía previa, con la consiguiente hambruna y debilitamiento de la población; las primeras señales de un morbo introducido (¡la historia se repite!) por tropas extranjeras de paso. Las descripciones bellísimas y minuciosas se alternan con las menciones de las fuentes históricas: consultándolas, Manzoni viene en contacto con 
dos elementos importantísimos, que se descuidan en las dos descripciones anteriores, de Tucídides y Boccaccio. El primero es la ceguera de los hombres frente al manifestarse de la catástrofe, como si negando su evidencia se cancelara el peligro; y ceguera y negación frente a los sabios avisos de la sensatez y la experiencia (se menciona el protomédico de entonces, Ludovico Settala, al que está hoy dedicada una importante calle de Milán, pero cuyos consejos de sabia precaución en su época fueron sistemáticamente desoídos).

Pero cuando la epidemia se manifiesta en toda su virulencia, surge fortísimo otro fenómeno nefasto: la gente busca, quiere, exige un culpable. Y como durante la carestía previa al contagio la población había asaltado las panaderías gritando que el gobierno "escondía" la harina (el pan cotidiano) para encarecerla, ahora está atenta a toda señal sospechosa de transeúntes, de amigos y vecinos, para acusarlos de "untar" las puertas de la gente de bien con la sustancia ponzoñosa. ${ }^{4}$ El gobierno español favorece estas acusaciones en contra de infelices víctimas, con tal de no ser el objeto directo del furor popular. Fuera de la novela, en la que el asunto se menciona colateralmente y hasta involucra brevemente al protagonista, Manzoni tratará sobre bases documentales, de la muerte atroz después de un juicio basado sólo sobre la tortura, de dos infelices acusados de propagar la peste untando puertas, en su ensayo Storia della colonna infame.

Manzoni no se detiene mucho sobre la sintomatología física, porque la moral y espiritual le interesan mucho más. El comportamiento de la gente, el horror, la desesperación, el egoísmo y, librándose sobre todo esto, las supremas virtudes: la caridad que resplandece en la dedicación de los religiosos que atienden, a costa de su vida, a los enfermos; la capacidad del perdón en lugar del regocijo, cuando el que se ve postrado por la enfermedad mortal es el enemigo.

Manzoni es un narrador, escribe una novela, y entre los detalles históricos a menudo reforzados con la mención o la cita de la fuente, narra acerca de personajes y episodios que son emblemáticos y posibles, pero que salen de su capacidad creadora. Son históricos los recogedores de cadáveres — en casas o abandonados en la calle- que, enfermos curados del mal y, como diríamos hoy, inmunizados frente a una recaída, pueden hacer el bajo y tremendo oficio sin riesgo, en vista de despojos y otras ganancias, temidos y odiados por todos. El nombre que se les daba era de monatti. ${ }^{5}$ Hay, en el cap. XXXIII, un episodio justamente célebre que nos describe Manzoni, que bien puede darnos la medida de cómo el escritor ve y trata esta tragedia: el de la madre de la niña Cecilia que entrega con sumo cuidado a su hijita muerta a un monatto que, sobrecogido de emoción, respeta la delicadeza de la madre: que le pide volver por ella y la otra hija, enfermas ambas, en la noche (Manzoni: 895).

Manzoni es demasiado puro y profundo en su sentimiento religioso como para atribuir a Dios la voluntad de castigar a la humanidad con una plaga semejante. El Dios

\footnotetext{
${ }^{4}$ El nombre que se les daba era, de hecho, untori, es decir, untadores.

${ }^{5}$ Una etimología explicativa de monatto no se conoce. Pertenece el término al dialecto milanés, como equivalente de becchino, analizado antes, pero hoy significa muchacho, mozuelo.
} 
de la religión católica permite que la naturaleza haga su curso, pero, atento a todas sus criaturas, toca a unas el corazón para que encuentren una nueva dimensión en la vida y la muerte, a otras las libera de los afanes, a otras premia con una muerte noble; para todos hay un más allá en que tendrán, podrán, querrán dar cuenta a Dios de su vida directamente, trascendiendo el juicio limitado y mezquino de los hombres.

La palingenesia, el re-nacimiento después de la catástrofe (y es tremendo recordar que, a principio del siglo Xx, los Futuristas proclamaron esta palingenesia definiendo la guerra "sola higiene del mundo"; y para un intelectual como Papini ¡la guerra tenía el valor de una benéfica limpieza profunda de la sociedad! ${ }^{6}$ ), este renacimiento para Manzoni es todo interior, es un regreso a los valores profundos de la vida, gracias a la contemplación de la muerte.

\section{Camus}

Los tres autores que hemos examinado hasta aquí tienen ideologías distintas, pero todos atribuyen a la naturaleza, a su curso inescrutable, la causa de estas tragedias. Me gusta citar en este punto una frase de un estudiante de Letras Italianas, Sebastián Manterola, en un ensayo sobre el concepto de Naturaleza en Giacomo Leopardi: "La lucha de la sociedad contra la naturaleza siempre será vencida por la naturaleza, que es más antigua y que rige todas las acciones humanas". La creencia en Dios no excluye esta visión de los hechos; en palabras del joven estudioso, que escribe estas palabras a propósito de un autor no religioso, Leopardi, que se sobrecoge en la contemplación de los estragos del volcán Vesubio, constata que el poeta, a pesar del "sentimiento ateísta de su obra, [convierte] la naturaleza en una fuerza rectora del Universo, que sin tener una verdadera conciencia divina, funciona como un elemento invisible que conforma el orden cósmico". Y este mismo sentimiento de impotencia frente a las inexplicables leyes naturales es el que configura el último gran texto dedicado a la peste, la novela que de este flagelo toma el título, La peste, de Albert Camus (1913-1960).

Camus escribe una novela sin bases históricas: la temática relativa a la plaga no se sostiene sobre un hecho real. La mortandad se manifiesta en una sola ciudad, Oran, en Argel; primero mueren a millares las ratas, y luego los hombres, en la ciudad que por orden médico se aísla del resto del mundo, en cuarentena. Todos los protagonistas, los múltiples personajes de su espléndida narración, ven su vida trastocada por el flagelo: material y espiritualmente. Y demostrando una penetración extraordinaria en el alma humana, Camus nos hace ver cómo el protagonista, el Doctor Rieux, que es agnóstico,

\footnotetext{
${ }^{6}$ En su Manifiesto, publicado en París en Le Figaro el 2 de febrero 1909, el texto del art. 9 así empieza: "Nous voulons glorifier la guerre — seule hygiène du monde..." Y Giovanni Papini, a orillas de la entrada en guerra de Italia, en 1914, escribe un entero artículo en la revista Lacerba, "Amiamo la guerra", donde encontramos una frase como ésta: "Siamo troppi. La guerra è un'operazione malthusiana". O sea una forma de control de la población, ya excesiva...
} 
refuerza su negación de Dios frente a la muerte de un inocente; mientras que el sacerdote que lo acompaña siente reforzarse su fe, y le aconseja de "aimer ce que nous ne pouvons pas comprendre", obtiene sólo la respuesta rebelde del doctor: "Je réfuserai jusqu'à la mort d'aimer cette création où des enfants sont torturés" (Camus: 238). Son las dos posturas espirituales frente a la tragedia de la vida: es el tema profundo de la novela que es imposible analizar sólo superficialmente. A esa peste que se describe a lo largo de toda la narración - comienzo, síntomas, virulencia, declino y desaparición- se le han atribuido valores metafóricos: la dictadura, principalmente.

A nosotros aquí nos importa subrayar cómo este fenómeno tremendo no ha sido pasado por alto por parte de los historiadores, ha sido integrado en obras literarias de signo diferente hasta constituir el tema único de una novela fundamental, justo en el siglo XX, pocos años antes que la difusión del uso de los antibióticos pusiera fin para siempre a este tipo de contagio bacteriano. Pero no a este tipo de tragedia, que se manifiesta ahora con las modalidades más sutiles y hasta ahora invencibles de los contagios virales. Pues el destino del hombre en poder de la naturaleza no ha cambiado. Pero en todos estos casos, el flagelo al pasar deja detrás de sí una estela de renovación: histórica, social o individual. Y siempre conlleva, este renacimiento, una profundización espiritual que nos motiva a reflexionar sobre lo que trasciende nuestra frágil vida.

\section{Obras consultadas}

Boccaccio, Giovanni. Decamerón. Trad. Esther Benítez. Madrid: Alianza Editorial, 1987. Impreso.

CAMus, Albert. La peste. París: Gallimard, 1947. Impreso.

MAnZONI, Alessandro. I promessi sposi. Opere. Ed. Riccardo BACCHELLI. Milán / Nápoles: Ricciardi, 1953. Pp. 393-959. Impreso.

. Storia della colonna infame. Opere. Ed. Riccardo BACCHELLI. Milán / Nápoles: Ricciardi, 1953. Pp. 961-1052. Impreso.

THUCYDIDES. The History of Peloponnesian War. Notas Thomas ARNOLD. Londres: Whittaker, 1840. Impreso.

Tucidide. La guerra del Peloponneso. Trad. Piero SGRoI. Milán: Istituto per gli Studi di Politica Internazionale, 1942. Impreso. 
